\title{
Comparison of the efficacy of two combined therapies for peptic ulcer bleeding: adrenaline injection plus haemoclipping versus adrenaline injection followed by bipolar electrocoagulation
}

\author{
Agnieszka Świdnicka-Siergiejko, Mariusz Rosołowski, Eugeniusz Wróblewski, Andrzej Baniukiewicz, \\ Andrzej Dąbrowski
}

Department of Gastroenterology and Internal Medicine, Medical University of Bialystok, Bialystok, Poland

Prz Gastroenterol 2014; 9 (6): 354-360

DOI: $10.5114 / p g .2014 .47898$

Key words: endoscopy-interventional, gastroduodenal-clinical, gastrointestinal-bleeding, peptic ulcer disease, Gold-Probe.

Address for correspondence: Mariusz Rosołowski MD, PhD, Department of Gastroenterology and Internal Medicine, Medical University of Bialystok, 26 a M. Sklodowska-Curie St, 15-276 Bialystok, Poland, phone: +48 8574682 34, e-mail: Mariusz.Rosolowski@umb.edu.pl

\begin{abstract}
Introduction: Peptic ulcer remains the most frequent cause of upper gastrointestinal bleeding. Treatment of bleeding with simultaneous combination of two endoscopic techniques has proved to be more efficient than monotherapy. None of the published comparative studies of various contact coagulation modalities have confirmed the superiority of one of these techniques over the others.

Aim: To compare the therapeutic outcomes of the use of a device enabling both injection of adrenaline solution and bipolar electrocoagulation $(A+B E)$ to those of combined adrenaline injection with mechanical therapy (haemostatic clips) $(A+H C)$ in the treatment of peptic ulcer bleeding.

Material and methods: Fifty-two subjects with bleeding ulcers were assigned to the $A+B E$ group, and 55 patients were treated with $\mathrm{A}+\mathrm{HC}$.

Results: Overall, treatment failed in 20 patients (20/107, 18.7\%): in 10 individuals from the A + BE group (10/52; 18.2\%) and in 10 individuals from the A + HC group $(10 / 55 ; 19.2 \%)(p>0.05)$. Primary haemostasis was not obtained in 7 patients $(6.5 \%)$ : in 4 patients in the $A+B E$ group and in 3 patients in the $A+H C$ group $(p>0.05)$. Ten individuals (9.3\%) experienced recurrent bleeding during hospitalisation: 4 patients from the $\mathrm{A}+\mathrm{BE}$ group and 6 patients from the $\mathrm{A}+\mathrm{HC}$ group $(p>0.05)$. Finally, in $96.3 \%$ of the patients $(n=103)$ the endoscopic treatment proved efficient with regards to obtaining haemostasis during hospitalisation. Surgical intervention was required in 4 individuals (3.7\%): 2 patients in the $A+B E$ group and 2 patients treated with $A+H C$ $(p>0.05)$. Three patients $(2.8 \%)$ - all from the A + HC group - died during hospitalisation. No significant intergroup differences were documented with regards to the mean number of transfused blood units and the mean length of hospital stay.

Conclusions: The efficacy of combined endoscopic treatment of ulcer bleeding with a probe enabling simultaneous bipolar electrocoagulation and adrenaline injection seems comparable to the widely used dual technique of adrenaline injection and haemostatic clipping.
\end{abstract}

\section{Introduction}

Gastrointestinal bleeding is one of the most frequent emergency states in gastroenterology, and it is characterised by considerable incidence and mortality. The incidence of gastrointestinal bleeding amounts to 50-150 cases per 100,000, and peptic ulcer bleeding remains the most frequent cause of upper gastrointestinal bleeding. Despite significant progress observed in recent years, related to the implementation of endoscopy and the availability of newer and more sophisticated methods of endoscopic treatment and therapy inhibiting the secretion of hydrochloric acid, the mortality still ranges between $3 \%$ and $14 \%$. The mortality is documented mostly in individuals above 60 years of age, especially in those with other advanced comorbidities [1-8].

Several endoscopic findings have a higher risk for recurrent bleeding - the probability of bleeding recurrence in patients with actively bleeding ulcer and ulcer with visible vessel is $100 \%$ and $50 \%$, respectively [3]. Clini- 
cal research suggests that in those patients endoscopic therapy can markedly reduce morbidity and mortality [3]. The efficacy of many methods, including injection techniques, mechanical techniques, contact coagulation (e.g. heat probe), and non-contact coagulation (e.g. argon plasma coagulation - APC), is comparable. None of the published comparative studies of various contact coagulation modalities have confirmed the superiority of any one of these techniques over the others. Recently, combining two different endoscopic techniques has been recommended. The combination of injection and mechanical or thermal technique has proved to be more efficient than injection monotherapy [3, 9-11].

Gold Probe ${ }^{T M}$ is one of the methods of bipolar contact coagulation. The round distal tip of the probe and specific orientation of the electrode pair enables good contact with the tissue surface, which is reflected by effective coagulation irrespective of probe position. Additionally, by using the Injection Gold Probe ${ }^{T M}$, which enables the simultaneous use of injection (adrenaline) and thermal method (bipolar electrocoagulation), replacing the probe is not required during examination, which shortens the duration of endoscopy and reduces the patient's discomfort. Therefore, adrenaline injection with bipolar electrocoagulation combined in one device seems to be a promising endoscopic method in the treatment of bleeding ulcers. The results of only a few studies involving bipolar electrocoagulation with injection of adrenaline have been published thus far; most of these studies were conducted in an experimental setting [12-15]. Moreover, no comparative studies of this modality and the most frequently applied technique, i.e. injection with the insertion of haemostatic clips, have been performed in the case of actively bleeding ulcers.

\section{Aim}

The aim of our study was to compare the therapeutic outcomes of bipolar electrocoagulation with injection of adrenaline (Injection Gold Probe) to those of combined injection of adrenaline solution and mechanical therapy with haemostatic clips in the treatment of peptic ulcer bleeding.

\section{Material and methods Patients}

We prospectively included in the study only patients with peptic ulcer bleeding treated with adrenaline injection and bipolar electrocoagulation (Injection Gold Probe), admitted between 2008 and 2011 to the Department of Gastroenterology and Internal Medicine, Medical University of Bialystok. For comparative analysis of endoscopic treatment outcome, from all patients hospitalised in the same period time due to upper gastrointestinal bleeding, we retrospectively matched the control group consisting of patients with peptic ulcer bleeding treated with adrenaline injection combined with haemostatic clipping. All patients (aged over 18 years) had peptic ulcer bleeding requiring endoscopic intervention (according to the Forrest scale: grade Iactive bleeding - spurting or oozing; grade Ila - ulcer with visible non-bleeding vessel) $[16,17]$. Exclusion criteria included the following: (1) inactive bleeding not requiring endoscopic intervention, (2) non-ulcer bleeding, and (3) use of other endoscopic techniques, e.g. monotherapy (adrenaline injection, clipping, heater probe). All patients expressed their written informed consent for the endoscopic therapy.

The following information was obtained from all the patients: (1) demographic data: age, gender; (2) number of patients in whom bleeding occurred during hospitalisation or in an outpatient setting; (3) bleeding episodes; (4) comorbidities - diseases of liver (cirrhosis, chronic hepatitis, fatty liver disease), heart (ischaemic disease, history of myocardial infarction), lungs (chronic obstructive pulmonary disease, asthma), kidneys (chronic renal failure), central nervous system (CNS) (history of stroke, transient ischaemic attack), diabetes; (5) arterial blood pressure and pulse on admission; and (6) laboratory parameters on admission, including the serum level of haemoglobin $(\mathrm{Hb})$, haematocrit, platelet count, urea, creatinine, bilirubin, alanine aminotransferase (ALT), and aspartate aminotransferase (AST). The risk of recurrent bleeding and mortality was assessed with the Rockall score $[4,8,18]$.

\section{Treatment}

All patients were treated according to the current guidelines [9, 10, 18]: omeprazole (intravenously, $80 \mathrm{mg}$ in bolus, followed by 72 -hour infusion at $8 \mathrm{mg} / \mathrm{h}$ ), and optimisation of vascular bed (1000-2000 ml of physiological saline or polyelectrolyte solution). The lack of haemodynamic compensation after fluid administration constituted indication to the transfusion of blood preparations.

Endoscopy was performed within $24 \mathrm{~h}$ after admission by one of three experienced specialists. All endoscopic techniques were used on a routine basis, following the manufacturer's instructions and recommendations. Olympus (GIF-Q165) therapeutic endoscopes were used for all procedures. In general, diluted ( 1 : 10,000 in saline) adrenaline was injected in 0.5-2 ml aliquots in and around the stigmata of haemorrhage in the ulcer base until active bleeding slowed or stopped. Clips (Olympus, HX-610-135) were placed (1-3 clips) over the bleeding site and on either side of the stigmata in 
an attempt to seal the underlying artery. Bipolar electrocoagulation was performed with Injection Gold Probe ${ }^{T M}$ Bipolar Haemostasis catheter (Boston Scientific), which was applied as close as possible to the bleeding point or visible vessels (setting 15-20 W); energy was delivered in 8-10-second pulses. Prior to coagulation, injection of adrenaline solution (in 1 to $2 \mathrm{ml}$ boluses) to the surrounding area of the bleeding site was performed by using the gauge inside the probe.

\section{Treatment outcomes}

The therapeutic outcomes were compared between the two groups of patients identified on the basis of the employed endoscopic technique: adrenaline injection + haemostatic clips ( $+\mathrm{HC}$ group) vs. adrenaline injection + bipolar electrocoagulation ( $+B C$ group). The following parameters were determined in both groups: (1) frequency of recurrent bleeding, (2) necessity of surgical intervention, (3) hospital mortality, (4) length of hospital stay, and (5) number or transfused blood units or blood preparations. Treatment failure was defined as the lack of primary haemostasis, recurrent bleeding, necessity of surgical intervention, or patient death. The primary haemostasis was defined as haemostasis obtained during the initial endoscopic treatment, and the lack of bleeding 5 min thereafter. Recurrent bleeding was defined as an episode of further bleeding oc- curring after primary haemostasis, and manifesting as haematemesis and/or melena co-existing with signs of haemodynamic instability (systolic blood pressure below $100 \mathrm{~mm} \mathrm{Hg}$, heart rate over 100 beats per minute, or a decrease in $\mathrm{Hb}$ by about $2 \mathrm{~g} / \mathrm{dl}$ during $24 \mathrm{~h}$ ). Patients with recurrent bleeding were subjected to a second endoscopy. The inability to obtain haemostasis with endoscopic techniques constituted indication to surgical intervention [18].

\section{Statistical analysis}

Relative (\%) frequency measurements in the qualitative variables were used for the descriptive analysis of the characteristics of the patients. Continuous variables were expressed as means and standard deviations. The differences between qualitative variables were determined by using $\chi^{2}$ tests. Comparison of quantitative variables between the two treatment groups was performed using the Mann-Whitney $U$ test. A $p$-value $<0.05$ was required for significance. Calculations were performed with the use of the Statistica 10 statistical package.

\section{Results}

\section{Characteristics of the patients}

During the analysed period, 353 patients were admitted due to signs of upper gastrointestinal bleed-

Table I. Risk stratification

\begin{tabular}{|c|c|c|c|}
\hline Parameter & $A+B C$ group $(n=52)$ & $\mathrm{A}+\mathrm{HC}$ group $(n=55)$ & Value of $p$ \\
\hline Gender, M/F, $n(\%)$ & $29(55.8 \%) / 23(44.2 \%)$ & $36(65.5 \%) / 19(34.5 \%)$ & 0.305 \\
\hline Age, mean (SD, min-max) [years] & $66.8(16.1,30-92)$ & $62.7(18.9,21-95)$ & 0.277 \\
\hline \multicolumn{4}{|l|}{ Episode of bleeding, $n(\%)$ : } \\
\hline First & $44(84.6)$ & $47(85.5)$ & 0.903 \\
\hline Second and subsequent & $8(15.4)$ & $8(14.5)$ & \\
\hline \multicolumn{4}{|l|}{ Onset of primary bleeding, $n(\%)$ : } \\
\hline At hospital & $14(26.9)$ & $13(23.6)$ & 0.696 \\
\hline Outside hospital & $38(73.1)$ & $42(73.4)$ & \\
\hline \multicolumn{4}{|l|}{ Comorbidities, $n$ (\%): } \\
\hline Heart & $34(65.4)$ & $32(58.2)$ & 0.261 \\
\hline Lungs & $7(13.5)$ & $12(21.8)$ & 0.261 \\
\hline Kidneys & $11(21.2)$ & $11(20.0)$ & 0.883 \\
\hline CNS & $4(7.7)$ & $6(10.9)$ & 0.811 \\
\hline Liver & $10(19.3)$ & $10(18.2)$ & 0.889 \\
\hline Malignancy & $5(9.6)$ & $3(5.5)$ & 0.653 \\
\hline Mean Rockall score, mean (SD) & $4.8(2.3)$ & $4.5(2.1)$ & 0.493 \\
\hline \multicolumn{4}{|l|}{ Forrest grade, $n(\%)$ : } \\
\hline I & $25(48.1)$ & $22(40.0)$ & 0.400 \\
\hline $\mathrm{Ila}$ & $27(51.9)$ & $33(60.0)$ & \\
\hline
\end{tabular}


Table II. Physical examination and laboratory data

\begin{tabular}{lccc}
\hline Parameter, mean (SD) & A + BC group $(n=52)$ & A + HC group $(n=55)$ & Value of $p$ \\
\hline Pulse $[$ beats/min] & $91.6(21.2)$ & $93.9(16.3)$ & 0.306 \\
\hline Systolic blood pressure $[\mathrm{mm} \mathrm{Hg}]$ & $122.3(22.6)$ & $120.6(19.6)$ & 0.492 \\
\hline Haemoglobin $[\mathrm{g} / \mathrm{dl}]$ & $8.4(2.0)$ & $8.6(1.8)$ & 0.389 \\
\hline Haematocrit $(\%)$ & $25.3(6.5)$ & $25.7(5.5)$ & 0.717 \\
\hline Platelet count $\left[10^{3 / \mu l]}\right.$ & $211.6(108.1)$ & $210.2(96.1)$ & 0.801 \\
\hline INR & $1.9(2.7)$ & $1.7(2.1)$ & 0.830 \\
\hline Fibrinogen $[\mathrm{mg} / \mathrm{dll}]$ & $269.8(126.6)$ & $321.6(129.6)$ & 0.051 \\
\hline Blood urea $[\mathrm{mg} / \mathrm{dl}]$ & $85.7(80.0)$ & $91.6(47.3)$ & 0.087 \\
\hline Creatinine $[\mathrm{mg} / \mathrm{dl}]$ & $1.45(1.6)$ & $1.2(0.8)$ & 0.359 \\
\hline Bilirubin $[\mathrm{mg} / \mathrm{dl}]$ & $1.6(3.3)$ & $1.1(0.5)$ & 0.446 \\
\hline Alanine aminotransferase $[\mathrm{IU} / \mathrm{l}]$ & $25.07(30.1)$ & $30.3(60.9)$ & 0.177 \\
\hline Aspartate aminotransferase $[\mathrm{IU} / \mathrm{l}]$ & $44.7(91.7)$ & $21.1(10.1)$ & 0.723
\end{tabular}

ing. The inclusion criteria of the study were fulfilled by 107 patients. Fifty-two subjects (52/107; 49\%) with bleeding ulcers were assigned to the $A+B E$ group. Another 55 patients $(55 / 107 ; 51 \%)$ were treated with $\mathrm{A}+\mathrm{HC}$. The characteristics of the studied group are presented in Tables I and II.

On admission, the analysed groups did not differ significantly in terms of age, gender, presence of comorbidities, and Rockall scores. In 91 patients (91/107; 85\%) the present episode was the first episode of bleeding. Forty-seven individuals (47/107; 43.9\%) presented with active bleeding corresponding to Forrest grade I, and 60 patients $(60 / 107 ; 56.1 \%)$ had a visible vessel (Forrest grade IIa). The analysed groups did not differ significantly with regards to the frequency of the abovementioned parameters (Table I).

Additionally, the studied groups did not differ significantly in terms of basic laboratory parameters determined on admission (Table II).

\section{Failures of treatment}

The therapeutic outcomes are summarised in Table III. Treatment failed in 20 patients (20/107; 18.7\%): in 10 individuals from the $A+B C$ group $(10 / 52 ; 18.2 \%)$ and in 10 individuals from the A + HC group (10/55; 19.2\%) $(p=0.889)$. Primary haemostasis was not obtained in 7 patients (7/107; $6.5 \%)$ : in 4 patients $(4 / 52 ; 7.7 \%)$ from the $A+B C$ group and in 3 patients $(3 / 55 ; 5.5 \%)$ from the $A+H C$ group $(p=0.939)$. Ten individuals $(10 / 107$; 9.3\%) experienced recurrent bleeding during hospitalisation: 4 patients from the $A+B C$ group (4/52; 7.7\%) and 6 patients from the A + HC group $(6 / 55 ; 10.9 \%)$ ( $p=0.811)$. Finally, in $96.3 \%$ of the patients $(103 / 107)$ the endoscopic treatment proved efficient with regards to obtaining haemostasis; among them were 50 out of
52 individuals from the $A+B C$ group, and 53 out of 55 individuals from the $A+\mathrm{HC}$ group. Surgical intervention was required in 4 individuals (4/107; 3.7\%): in 2 patients in the $A+B C$ group and in 2 patients treated with $A+\mathrm{HC}(p=0.651)$. Three patients $(3 / 107 ; 2.8 \%)$ died during hospitalisation. All those patients were from the $\mathrm{A}+\mathrm{HC}$ group patients, and they died during hospitalisation mainly due to complications of other serious comorbidities (1 patient with acute coronary syndrome, 1 patient with pneumonia along with cardiovascular and pulmonary insufficiency, and 1 patient with liver insufficiency).

\section{Transfusion of erythrocyte concentrates}

Eighty-five individuals (85/107; 79.4\%) required transfusion of erythrocyte concentrate, among them 44 patients from the $A+B C$ group $(44 / 52 ; 84.6 \%)$ and 41 patients from the $A+H C$ group $(41 / 55 ; 74.5 \%$; $p=0.199)$. The mean number of transfused erythrocyte concentrate units was similar in both subgroups (Table III).

\section{Duration of hospitalisation}

The mean length of hospital stay of patients from the $A+B C$ group and the $A+H C$ group was 9.1 and 9.0 days, respectively. This difference did not prove significant on statistical analysis (Table III).

\section{Discussion}

Our study compared the efficacy of two methods of combined endoscopic treatments of actively bleeding ulcers: adrenaline with bipolar electrocoagulation and adrenaline injection with clipping. Both techniques represent examples of a combined approach, which is considered the best amongst all currently recommended 
Table III. Clinical data

\begin{tabular}{|c|c|c|c|}
\hline Parameter & $A+B C$ group $(n=52)$ & $A+\mathrm{HC}$ group $(n=55)$ & Value of $p$ \\
\hline Treatment failure, $n(\%)$ : & $10(18.2)$ & $10(19.2)$ & 0.889 \\
\hline Lack of primary haemostasis & $4(7.7)$ & $3(5.5)$ & 0.939 \\
\hline Recurrent bleeding & $4(7.7)$ & $6(10.9)$ & 0.811 \\
\hline Necessity of surgical intervention & $2(3.8)$ & $2(3.6)$ & 0.651 \\
\hline Death & $0(0.0)$ & $3(5.5)$ & 0.262 \\
\hline Successful endoscopic treatment, $n(\%)$ & $50(96.2)$ & $53(96.4)$ & 0.651 \\
\hline \multicolumn{4}{|l|}{ Transfusion of erythrocyte concentrate: } \\
\hline Patients requiring transfusion, $n(\%)$ & $44(84.6)$ & $41(74.5)$ & 0.199 \\
\hline Number of transfused units, mean (SD) & $2.9(2.4)$ & $2.7(2.6)$ & 0.349 \\
\hline Number of transfused FFP units, mean (SD) & $0.75(1.6)$ & $0.87(1.9)$ & 0.739 \\
\hline Length of hospital stay, mean (SD) [days] & $9.1(4.7)$ & $9.0(4.3)$ & 0.816 \\
\hline
\end{tabular}

treatment modalities for non-variceal upper gastrointestinal bleeding $[3,9,10,18]$. The efficacy of these two techniques had not been compared previously.

Although adrenaline injection in monotherapy is characterised by nearly $100 \%$ efficacy (i.e. primary haemostasis) in the case of active bleeding, it does not reduce the incidence of recurrent bleeding or the necessity of surgical intervention $[11,19,20]$. The administration of adrenaline in monotherapy is inferior to other monotherapeutic modalities (bipolar electrocoagulation, clips, fibrin glue) with regards to the prevention of recurrent bleeding and surgical treatment [11]. In contrast, combining adrenaline injection with another technique (e.g. bipolar electrocoagulation, sclerotising agents, and clips) is significantly more effective in preventing recurrent bleeding, and surgical treatment as compared to the administration of adrenaline alone [11, 21, 22].

A meta-analysis of 15 randomised trials revealed that thermal methods are more efficient in terms of obtaining primary haemostasis and are associated with lower frequency of surgical intervention and lower mortality as compared to the absolute lack of endoscopic treatment [11]. However, the previously mentioned meta-analyses did not distinguish between the methods involving multipolar or bipolar electrocoagulation probes. In randomised trials comparing these two thermal methods no significant differences were seen [11]. A comparison of combined approach, including adrenaline injection and thermal method, with the lack of endoscopic therapy was the subject of three trials [23-25]; the combined therapy proved significantly better with regards to the prevention of further bleeding, but not in the case of surgical treatment and mortality.

Jutabha et al. [13] and Sugawa et al. [15] were the first to describe the use of bipolar electrocoagulation prototypes in combination with injection therapy (a prototype of Injection Gold Probe). The advantages of their prototype included the ability to irrigate, inject, and coagulate without probe removal $[13,15]$. In another study the use of bipolar electrocoagulation with 10-Fr catheter after adrenaline injection was associated with a reduced number of electrocoagulation procedures and shorter duration of the procedure as compared to 7- $\mathrm{Fr}$ catheter alone [26]. Laine et al. [27, 28] determined the optimal technique for bipolar electrocoagulation treatment.

Two small studies compared the efficacy of bipolar electrocoagulation combined with adrenaline injection (Injection Gold Probe, 7F) and the efficacy of bipolar electrocoagulation alone $[12,14]$. According to Bianco et al. [12], the frequency of obtaining haemostasis was higher in the case of the combined approach (absolute risk reduction $31.6 \%$ ). No differences were documented in the prevalence of other endpoints: the need for surgical intervention, length of hospital stay, and mortality. The only exception pertained to significantly fewer blood units transfused in the combined therapy group [12]. Lin et al. [14] compared the outcomes in patients with actively bleeding ulcers (I and IIa, according to the Forrest scale) treated with three various methods: adrenaline alone, bipolar electrocoagulation alone (Gold Probe), and the combination of both (Injection Gold Probe). Recurrent bleeding was less frequent in the Injection Gold Probe group (2/30, 6.7\%) than in the Gold Probe group (9/30, 30\%; $p=0.04)$ and in the adrenaline group (11/31, 35.5\%; $p=0.01)$. Additionally, individuals who received the combined therapy required fewer transfused blood preparations. In contrast, the analysed groups did not differ significantly with regards to the frequency of surgical intervention, the length of hospital stay, and mortality [14]. Although the number of high-quality studies is insufficient to confirm this hy- 
pothesis, it was postulated that adrenaline followed by thermal contact therapy may be more efficacious than thermal therapy alone [10].

We compared the efficacy of the most frequently applied endoscopic technique for the treatment of actively bleeding ulcers, i.e. adrenaline injection combined with clipping, with the efficacy of the combination of injection (with adrenaline) and thermal method (bipolar electrocoagulation). Both combined methods of endoscopic treatment were characterised by comparable efficacy. Recurrent bleeding was documented in $9.3 \%$ of the patients, among them 4 individuals were primarily subjected to the adrenaline with bipolar electrocoagulation group, and 6 patients were subjected to adrenaline injection with haemostatic clips. The epidemiological data reported that rebleeding in the upper gastrointestinal bleeding occurs in 7-16\% of cases despite endoscopic therapy and is especially high in variceal bleeding and peptic ulcer bleeding [1, 6]. However, the observed discrepancy of rebleeding rates might be caused by the use of different definitions of rebleeding and different endoscopic therapies, as well as heterogeneous sources of bleeding [1]. In our study surgical intervention was required in only 4 individuals ( 2 patients in each group), in whom haemostasis could not be obtained endoscopically. Moreover, there was a low mortality. Three patients, who were assigned to the adrenaline with haemostatic clips group, died during hospitalisation mainly due to complications of other serious comorbidities. There are large differences observed in the literature in the mortality, ranging from $3 \%$ to $14 \%$; mostly due to differences in case mix in the population-based surveys [1]. However, higher age, co-morbidity, the onset of bleeding in hospital patients, and rebleeding are significantly associated with mortality $[1,4]$. The mortality is very low in patients younger than 60 years of age without organ failure $[1,4,29]$.

Our study suffers from several limitations. The main flaw is that our study in not a randomised prospective study and therefore the conclusions should be regarded with caution. The lack of significant differences between the efficacies of various endoscopic techniques could result from a small number of patients included in our analysis. It is possible that a randomised controlled study with a higher number of patients enrolled would provide sufficient statistical power to show differences between both studied protocols. Moreover, we were unable to evaluate the long-term therapeutic outcomes, due to the retrospective character of our analysis. Follow-up of our patients was limited to the duration of their hospitalisation. Finally, we were unable to determine the duration of specific procedures, which precluded the comparison of this parameter between the subgroups.

\section{Conclusions}

Combined therapy is characterised by high efficacy in obtaining haemostasis of actively bleeding ulcer. In such cases, the efficacy of endoscopic treatment with a probe enabling simultaneous bipolar electrocoagulation and adrenaline injection seems comparable to the widely used dual technique of adrenaline injection and haemostatic clipping. However, due to the fact that the probe does not need to be removed and the consequent shorter duration of the procedure, this technique could become the therapy of choice in future in the case of active upper gastrointestinal bleeding. This has to be preceded by further prospective randomised trials of larger patient groups.

\section{References}

1. Atkinson RJ, Hurlstone DP. Usefulness of prognostic indices in upper gastrointestinal bleeding. Best Pract Res Clin Gastroenterol 2008; 22: 233-42.

2. British Society of Gastroenterology Endoscopy Committee. Non-variceal upper gastrointestinal haemorrhage: guidelines. Gut 2002; 51 Suppl. 4: iv1-6.

3. Hwang JH, Fisher DA, Ben-Menachem T, et al. The role of endoscopy in the management of acute non-variceal upper $\mathrm{Gl}$ bleeding. Gastrointest Endosc 2012; 75: 1132-8.

4. Rockall TA, Logan RF, Devlin HB, Northfield TC. Incidence of and mortality from acute upper gastrointestinal haemorrhage in the United Kingdom. Steering Committee and members of the National Audit of Acute Upper Gastrointestinal Haemorrhage. BMJ 1995; 311: 222-6.

5. Rockall TA, Logan RF, Devlin HB, Northfield TC. Risk assessment after acute upper gastrointestinal haemorrhage. Gut 1996; 38: 316-21.

6. Rosołowski M, Hartleb M, Marek T, et al. Therapeutic and prophylactic management of bleeding from oesophageal and gastric varices - recommendations of the Working Group of the National Consultant for Gastroenterology. Prz Gastroenterol 2014; 9: 63-8.

7. van Leerdam ME. Epidemiology of acute upper gastrointestinal bleeding. Best Pract Res Clin Gastroenterol 2008; 22: 209-24.

8. van Leerdam ME, Vreeburg EM, Rauws EA, et al. Acute upper GI bleeding: did anything change? Time trend analysis of incidence and outcome of acute upper GI bleeding between 1993/1994 and 2000. Am J Gastroenterol 2003; 98: 1494-9.

9. Barkun AN, Bardou M, Kuipers EJ, et al. International consensus recommendations on the management of patients with nonvariceal upper gastrointestinal bleeding. Ann Intern Med 2010; 152: 101-13.

10. Laine L, Jensen DM. Management of patients with ulcer bleeding. Am J Gastroenterol 2012; 107: 345-60.

11. Laine L, McQuaid KR. Endoscopic therapy for bleeding ulcers: an evidence-based approach based on meta-analyses of randomized controlled trials. Clin Gastroenterol Hepatol 2009; 7: 33-47.

12. Bianco MA, Rotondano G, Marmo R, et al. Combined epinephrine and bipolar probe coagulation vs. bipolar probe coagula- 
tion alone for bleeding peptic ulcer: a randomized, controlled trial. Gastrointest Endosc 2004; 60: 910-5.

13. Jutabha R, Jensen DM, Machicado G, Hirabayashi K. Randomized controlled studies of injection Gold Probes compared with monotherapies for hemostasis of bleeding canine gastric ulcers. Gastrointest Endosc 1998; 48: 598-605.

14. Lin HJ, Tseng GY, Perng CL, et al. Comparison of adrenaline injection and bipolar electrocoagulation for the arrest of peptic ulcer bleeding. Gut 1999; 44: 715-9.

15. Sugawa C, Takekuma Y, Lucas CE, et al. Experimental studies of thermal therapy for severe nonvariceal bleeding in dogs. Surg Endosc 1999; 13: 1203-7.

16. Forrest JA, Finlayson ND, Shearman DJ. Endoscopy in gastrointestinal bleeding. Lancet 1974; 2: 394-7.

17. Wu J, Sung J. Upper gastrointestinal bleeding diseases. In: Gastroenterological endoscopy. Classen M, Tytgat G, Lightdale C (eds). Thieme, Stuttgart 2002; 538-47.

18. Marek T, Baniukiewicz A, Wallner G, et al. Wytyczne postępowania w krwawieniu z górnego odcinka przewodu pokarmowego pochodzenia nieżylakowego [Polish]. Prz Gastroenterol 2008; 3: 1-22.

19. Chung SC, Leung JW, Steele RJ, et al. Endoscopic injection of adrenaline for actively bleeding ulcers: a randomised trial. $\mathrm{Br}$ Med J (Clin Res Ed) 1988; 296: 1631-3.

20. Rutgeerts P, Vantrappen G, Broeckaert L, et al. Comparison of endoscopic polidocanol injection and YAG laser therapy for bleeding peptic ulcers. Lancet 1989; 1: 1164-7.

21. Lo CC, Hsu PI, Lo GH, et al. Comparison of hemostatic efficacy for epinephrine injection alone and injection combined with hemoclip therapy in treating high-risk bleeding ulcers. Gastrointest Endosc 2006; 63: 767-73.

22. Vergara M, Calvet X, Gisbert JP. Epinephrine injection versus epinephrine injection and a second endoscopic method in high risk bleeding ulcers. Cochrane Database Syst Rev 2007; 2: CD005584.

23. Bleau BL, Gostout CJ, Sherman KE, et al. Recurrent bleeding from peptic ulcer associated with adherent clot: a randomized study comparing endoscopic treatment with medical therapy. Gastrointest Endosc 2002; 56: 1-6.

24. Jensen DM, Kovacs TO, Jutabha R, et al. Randomized trial of medical or endoscopic therapy to prevent recurrent ulcer hemorrhage in patients with adherent clots. Gastroenterology 2002; 123: 407-13.

25. Sung JJ, Chan FK, Lau JY, et al. The effect of endoscopic therapy in patients receiving omeprazole for bleeding ulcers with nonbleeding visible vessels or adherent clots: a randomized comparison. Ann Intern Med 2003; 139: 237-43.

26. Paspatis GA, Charoniti I, Papanikolaou N, et al. A prospective, randomized comparison of 10-Fr versus 7-Fr bipolar electrocoagulation catheter in combination with adrenaline injection in the endoscopic treatment of bleeding peptic ulcers. Am J Gastroenterol 2003; 98: 2192-7.

27. Laine L. Determination of the optimal technique for bipolar electrocoagulation treatment. An experimental evaluation of the BICAP and Gold probes. Gastroenterology 1991; 100: 107-12.

28. Laine L, Long GL, Bakos GJ, et al. Optimizing bipolar electrocoagulation for endoscopic hemostasis: assessment of factors influencing energy delivery and coagulation. Gastrointest Endosc 2008; 67: 502-8.

29. Paspatis GA, Matrella E, Kapsoritakis A, et al. An epidemiological study of acute upper gastrointestinal bleeding in Crete, Greece. Eur J Gastroenterol Hepatol 2000; 12: 1215-20.

Received: 19.10 .2014

Accepted: 23.10 .2014 